\title{
Bacteriological Study for Detection The Role of Fructan Produced from Pseudomonas putida as Enhancer for Lactobacillus acidophilus Growth
}

\author{
Alaa Raheem Kazim \\ Department of Biology, College of Science, University of Baghdad, Baghdad-Iraq. \\ Corresponding Auther: alaa_alkenane@yahoo.com.
}

\begin{abstract}
Fructan is a kind of biopolymer produced from plants, fungi, yeast and bacteria. It is classified as prebiotics food and enhanced the growth of probiotics bacterial strains which improves the health of the individual. This article aimed to study the production and extraction of fructan from Pseudomonas putida isolated from food samples and study the effect of fructan on the viable cell number of Lactobacillus acidophilus. The results showed that Pseudomonas putida have the ability to produce fructan when cultured on production medium (YPS), fructan exhibited as white powder when extracted from YPS and the amount of fructan was $3.6 \mathrm{mg} / 100 \mathrm{ml}$, also the results showed that fructan can increase the viable cell number of Lactobacillus acidophilus when added to MRS. FTIR analysis of fructan produced from Pseudomonas putida revealed that the functional groups found in chemical structure of fructan, which it was $(\mathrm{C}-\mathrm{O}, \mathrm{C}-\mathrm{H}, \mathrm{O}-\mathrm{H}$ and $\mathrm{C}=\mathrm{O})$.
\end{abstract}

[DOI: 10.22401/JUNS.21.1.15]

Keywords: Fructan, Prebiotics, Probiotics, Bifidobacteria, Lactobacilli and YPS medium.

\section{Introduction}

Fructan is extracellular polymers composed of $\mathrm{D}$-fructofuranosyl residues linked as either $\beta-(2,6)$ or $\beta-(2,1)$, the building units of fructan is fructose residues, and sucrose unit (glucose-fructose disaccharide) [1]. The location of linkage specified the type of fructan, in inuline the fructosyl residues are linked by $\beta$-2,1-linkages, while in levan (or Phlein), the fructosyl residues are linked by $\beta$-2,6-linkages with extensive branching through $\beta$ - $(2,1)$ linkages [2]. Graminan is a third type of fructan with $\beta$-2, 1-linkages and $\beta$-2, 6-linkages [3]. Fructan is produced by some plants, fungi, yeast and bacteria; Plant fructan is synthesized from sucrose by recurrent fructosyl transfer from a fructosyl donor, with a terminal glucose unit, and in the present of sucrose-sucrose fructosyl transferase enzyme which catalyses the transfer of a fructose molecule from one sucrose molecule to another, and formation of kestose [4]. Plant fructan synthesized in the form of linear inuline consisting of $\mathrm{B}(2 \rightarrow 1)$ fructofuranosyl units or more complex and branched levan consisting of $\mathrm{B}-(2 \rightarrow 6)$ fructofuranosyl units [4]. Microbial fructan is synthesized by recurring transfer of fructose from a fructosyl donor to the growing fructan chain, with much higher degree of polymerization (up to 100,000 ) than plant fructan (up to 150) [5]. Fructan producing bacteria were reported from the following genera: Pseudomonas, Zymomonas, Xanthomonas, Azotobacter, Erwinia, Streptococcus, Bacillus, and Arthobacter [6, 7]. Fructan can be hydrolyzed by fructanases (inulinase and levanase) to generate fructose [8], mammals do not produce fructanases, and hence fructan is considered indigestible polysaccharides [6,9], therefore serve as substrate for utilization by the intestinal microflora and undergo fermentation in the colon by the colonic microflora resulting in the formation of acetate, lactate, and short chain of fatty acid which benefit the host health by simplifying the absorption of minerals and improving the host health [10].

Fructan and short-chain fructo oligosaccharides (FOS) are considered as representative prebiotics due to their ability to preferentially stimulate the growth of intestinal bifidobacteria [11].

Prebiotics is one of a non digestible food ingredient, which enhance the host health by stimulation the growth of colonic bacteria. The plentiful in the number of bifidobacteria and lactobacilli in the human and animal large intestine due to the ingestion of fructan present several benefits to their host, such as the competitive exclusion of intestinal pathogens, reduction of serum cholesterol, increasing 
calcium and magnesium absorption, prevention of colon cancer, and production of B-vitamins [12].

Prebiotics also can be defined as enhancers of probiotic strains or beneficial endogenic strains of the gastrointestinal tract, therefore prebiotics selectively stimulate the growth of these microorganisms [13].

A probiotic is a mono - or mixed culture of living microorganism which beneficially affects the host by: Improving the properties of the indigenous population of gastro intestinal microorganisms, inhibition of pathogenic microorganisms, increasing the immune response and reduction of cholesterol levels with antimutagenic, anti carcinogenic activity $[12,14]$.

Bifidobacteria and lactobacilli have been used as probiotics, the beneficial effects of lactobacilli have been attributed to their ability to suppress the growth of pathogenic bacteria, possibly by secretion of antibacterial substances such as lactic acid, peroxide and bacteriocins [13,14]. Bifidobacteria and lactobacilli possess intracellular B (2-1)-dfructan-fructan hydrolyase activity making the fructan molecules an efficient substrate, dietary fructan that reach the colon may thus select for an enhanced growth and activity of the indigenous bifidobacteria and lactobacilli population [13].

The present study was carried out to detect the effect of fructan that extracted from Pseudomonas putida to enhance and increase the viable cell number of Lactobacillus acidophilus.

\section{Materials and Methods \\ Collection of samples}

Ten food samples (rice, meat, cream, cheese, potato, bread, chicken, tomato, apple and peach) were collected from different local markets in Baghdad governorate in clean sterile plastic containers; each food sample was given a special code number, transported to the laboratory until using.

\section{Isolation and identification of bacteria}

Half-gram of each food sample was added to $4.5 \mathrm{ml}$ of sterilized peptone water, mixed thoroughly and tenfold serial dilutions were done, MacConkey agar was prepared and inoculated with $100 \mu \mathrm{l}$ from the appropriate dilution $\left(1 \times 10^{7}\right)$, incubated at $37^{\circ} \mathrm{C}$ for $24 \mathrm{hrs}$. Fluorescing colonies was taken and streaked again on MacConkey agar plate and these steps were repeated several times till a pure culture was obtained and for full identification of bacterial isolates, VITEK 2 compact were done $[15,16]$.

\section{Production and Extraction of fructan from Pseudomonas putida}

Brain Heart Infusion broth (BHI) was used to activate bacterial culture, the activated bacterial culture was streaked on YPS agar plates $(1 \%$ yeast extract, $2 \%$ peptone and $5 \%$ sucrose), incubated at $30^{\circ} \mathrm{C}$ for $48 \mathrm{hrs}$. Bacterial colonies with sticky appearance were selected for production and extraction of fructan $[17,18]$.

\section{Identification of fructan by Fourier Transform Infrared Spectroscopy (FTIR)}

For complete the identification of fructan, (FTIR) spectroscopy was done as follows: Potassium bromide was mixed with the dried samples in ratio of $1: 10 \quad(w / w)$, and compressed to form a thin tablet. The tablet was instantly analyzed with a spectrophotometer [19].

\section{Study the effect of fructan to enhance the growth of Lactobacillus acidophilus}

To study the effect of fructan as enhancer for the growth of Lactobacillus acidophilus, MRS growth medium (De Man, Rogosa and Sharpe agar) was supplemented with $1 \%$ of fructan powder and the bacterial number was estimated before and after supplemented of fructan to the culture medium as follows [20]:

1. Lactobacillus acidophilus was activated in MRS broth and incubated an aerobically at $37^{\circ} \mathrm{C}$ for $24 \mathrm{hrs}$.

2. Control tube and test tube were prepared (control tube contained $10 \mathrm{ml}$ of MRS broth $+0.01 \mathrm{ml}$ activated bacterial culture, while test tube contained $10 \mathrm{ml}$ of MRS broth $+1 \%$ fructan $+0.01 \mathrm{ml}$ activated bacterial culture).

3. In order to calculate the initial cells number, tenfold serial dilution was done from $\left(10^{-1}-10^{-10}\right)$ for both tubes. 
4. MRS agar plates were prepared and inoculated with $0.01 \mathrm{ml}$ from each dilution from both tubes, incubated an aerobically at $37^{\circ} \mathrm{C}$ for $48 \mathrm{hrs}$.

5. To calculate the increasing in bacterial cells number, both tubes were incubated an aerobically at $37^{\circ} \mathrm{C}$ for $24 \mathrm{hrs}$, after that, serial dilutions were done from $10^{-1}-10^{-10}$ for both tubes.

6. From appropriate dilution $\left(1 \times 10^{6}\right)$ of both tubes, $0.01 \mathrm{ml}$ were transferred and spread on MRS agar plates, incubated an aerobically at $37^{0} \mathrm{C}$ for $48 \mathrm{hrs}$.

7. The viable cells number/ $\mathrm{ml}$ were calculated according to the formula:

$\mathrm{CFU}=$ number of colonies $\times$ dilution factor

8. Increasing in viable cells number were calculated according to the formula:

Increasing in viable cells number $(\%)=$

$\frac{\text { Viable cells number }- \text { Initial cells number }}{\text { Initial cells number }} \times 100$

\section{Results and Discussion \\ Isolation and Identification of Pseudomonas putida}

Ten food samples were taken and collected in clean sterile plastic containers. Study the morphological characteristics and microscopic examination, revealed that twenty-five of bacterial isolates were belonged to Pseudomonas spp. [21, 22].

Pseudomonas spp. was characterized by fluorescing colonies on MacConkey agar; Microscopic examination proved that it was Gram-negative bacteria, flagellated and nonspore former and for full identification of Pseudomonas putida VITEK 2 compact were done as showed in Fig.(1).

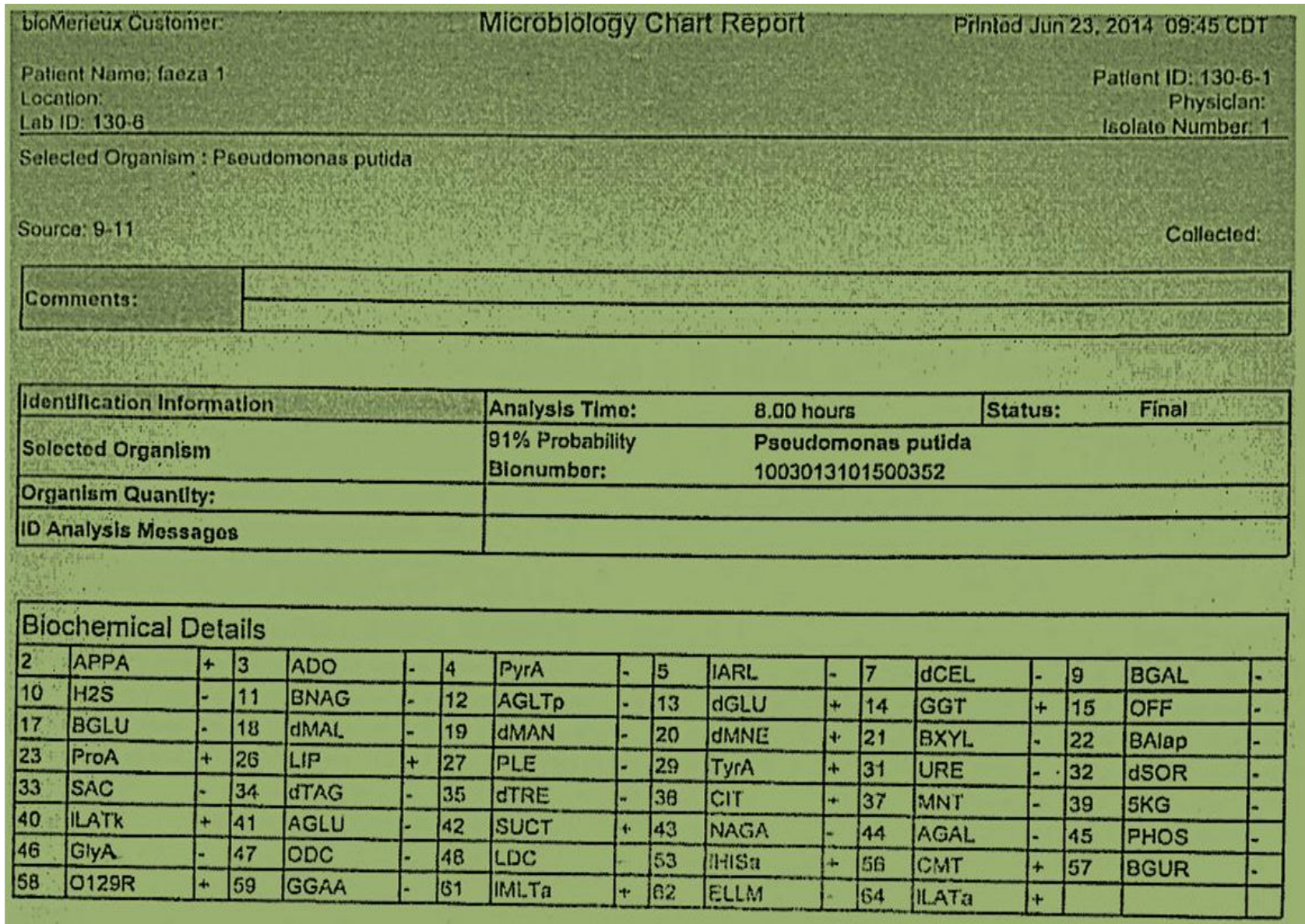

Fig.(1): VITEK2 compact identification for Pseudomonas putida. 


\section{Production and Extraction of Fructan from Pseudomonas putida}

Fructan was extracted from the production medium (YPS broth) with three volumes of 95\% cold ethanol; the amount of fructan was established by measuring the final dry weight of the precipitate after centrifugation. Fructan appeared as white powder and the dry weight was $3.6 \mathrm{mg} / 100 \mathrm{ml}$.

Cold ethanol lowering polysaccharide solubility, thus it was permitting their separations from the production media [23].

For the purification of fructan, repeating precipitation in ethanol and dissolution in water was performed [24, 25].

\section{Identification of Fructan by Fourier} Transform Infrared Spectroscopy (FTIR)

The infrared spectrum of this biopolymer showed the functional groups found in polysaccharides, which it was (C-O, C-H, O-H and $\mathrm{C}=\mathrm{O}) ; \mathrm{C}-\mathrm{H}$ and $\mathrm{O}-\mathrm{H}$ group bending in $\left(1223.85 \mathrm{~cm}^{-1}\right.$ and $\left.1450.03 \mathrm{~cm}^{-1}\right), \mathrm{C}-\mathrm{H}$ stretching in $\left(2819.73 \mathrm{~cm}^{-1}\right.$ and $\left.3000.01 \mathrm{~cm}^{-1}\right)$, $\mathrm{O}-\mathrm{H}$ stretching in $\left(3390.63 \mathrm{~cm}^{-1}\right.$ and $\left.3461.99 \mathrm{~cm}^{-1}\right), \mathrm{C}=\mathrm{O}$ and $\mathrm{C}-\mathrm{O}$ stretching group in $\left(1649.02 \mathrm{~cm}^{-1}\right.$ and $\left.1114.78 \mathrm{~cm}^{-1}\right)$ respectively. Fig. (2)

The absence of active groups present in nucleic acids and proteins demonstrates that the main component of the chemical composition of fructan compound is carbohydrates [26, 27].

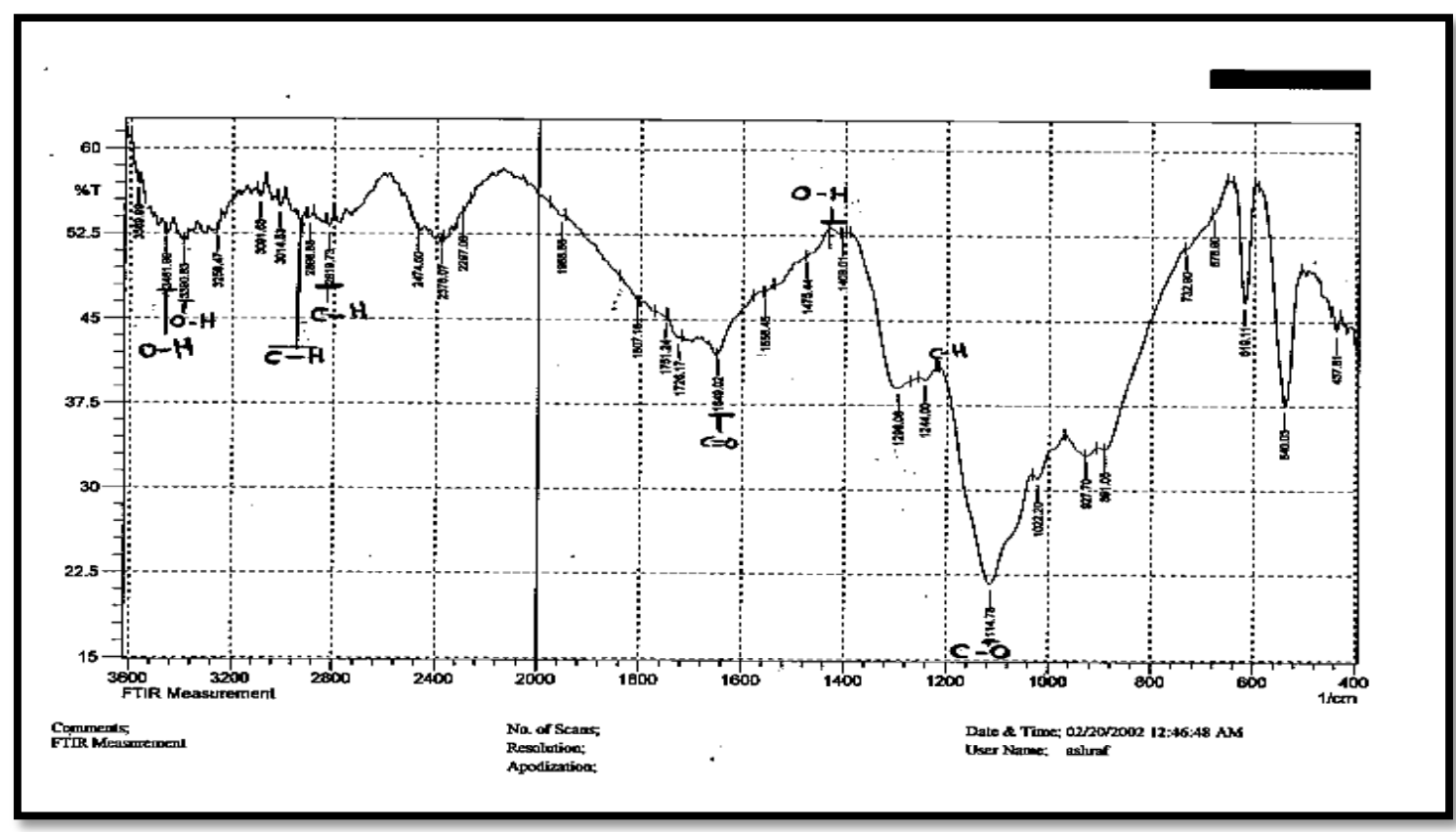

Fig.(2): FTIR analysis of fructan produced from Pseudomonas putida.

Study the effect of fructan as enhancer for the growth of Lactobacillus acidophilus

MRS medium was inoculated with Lactobacillus acidophilus before and after supplement the growth medium with $1 \%$ of fructan powder. The results was recorded depending on the viable cell number of bacteria on MRS and compared between the viable cell numbers of Lactobacillus acidophilus on MRS medium with and without supplement of fructan.

The results exhibited rising in the viable cells number of Lactobacillus acidophilus on MRS that supplied with fructan compared with control as showed in Table (1). 
Table (1)

Effect of fructan as enhancer for the growth of Lactobacillus acidophilus.

\begin{tabular}{|c||c||c||c||c||}
\hline $\begin{array}{c}\text { MRS } \\
\text { medium }\end{array}$ & $\begin{array}{c}\text { Initial cell no. } \\
(\text { Log } \text { CFU/ } \mathbf{m l})\end{array}$ & $\begin{array}{c}\text { Viable cell no. } \\
\text { after 48hrs. } \\
(\text { Log } \text { CFU/ml })\end{array}$ & $\begin{array}{c}\text { Increasing in } \\
\text { viable cell no. } \\
(\%)(\boldsymbol{a}) *\end{array}$ & $\begin{array}{c}\text { Increasing in viable } \\
\text { cell no. }(\%)(b) *\end{array}$ \\
\hline \hline Control & 4.07 & 6.57 & 61.42 & 31.5 \\
\hline \hline $1 \%$ fructan & 4.17 & 6.84 & 64.02 & 46.5 \\
\hline
\end{tabular}

* (a) The percentage was calculated according to log of viable cell number.

* (b) The percentage was calculated according to cell number.

From the table; it was clear that the existence of fructan in MRS medium had a role as enhancer for the growth of Lactobacillus acidophilus in addition to increase the viable cell number of it.

The logarithmic increasing in the viable cell number of Lactobacillus after the addition of levan at different concentration to growth medium proved that levan enhanced the growth of Lactobacillus acidophilus [20].

Lactobacillus acidophilus used specific enzymes (fructosidases) to hydrolyse B- $(2 \rightarrow 6)$ linkages present in carbohydrates structures and utilize it as substrate to enhance the growth of it [28].

The lowering in intestinal $\mathrm{pH}$, resulting from the fermentation of fructo oligosaccharide (FOS) by the mean of colonic normal flora have imprint in reducing the pathogenic bacteria by making the $\mathrm{pH}$ of the intestinal unsuitable for the growth of it [29].

\section{Conclusion}

Fructan extracted from Pseudomonas putida showed the ability to increase and enhanced the growth of Lactobacillus acidophilus when supplement the growth medium of Lactobacillus acidophilus (MRS) with $1 \%$ of fructan powder, FTIR analysis exhibited the essential groups present in fructan structure which it was $\mathrm{C}-\mathrm{O}, \mathrm{C}-\mathrm{H}, \mathrm{O}-\mathrm{H}$ and $\mathrm{C}=\mathrm{O}$.

\section{References}

[1] Jang K. H., Eun-Kyung J., Seung- Hwan K., In- Hwan K., Soon-Ah, K., Issac K., Young-Il P., Young-Jun K., Sang-Do H., and Chul H. K., "High-Level Production of Low-Branched Levan from Pseudomonas aurantiaca S-4380 for the Production of di- $\beta$-D- Fructofuranose Dianhydride IV.", J Microbiol Biotechnol., 16, 102-108, 2006.

[2] Donot F., Fontana A., Baccou J. C. and Schorr-Galindo S., "Microbial exopolysaccharides: Main examples of synthesis, excretion, genetics and extraction", Carbohydrate Polymers, 87, 951-962, 2012.

[3] Van den Ende W., "Multifunctional fructans and raffinose family oligosaccharides", Frontiers in Plant Science, 4, 1-11, 2013.

[4] Vijin I. and Smeekens S., "Fructan: more than a reserve carbohydrate", Plant Physiol., 120, 351-359, 1999.

[5] Narinder K. and Anilk G., "Applications of inulin and oligofructose in health and nutrition”, J. Biosci., 27, 703-714, 2002.

[6] Legaz M. E., Martin L., Pedrosa M. M., Vicente C., de Armas R., and Martinez M., "Purification and Partial Characterization of a Fructanase which Hydrolyzes Natural Polysaccharides from Sugarcane Juice", Plant Physiol., 92, 679-83, 1990.

[7] Richard J. J., Chris R., Miguel A. L., Silvia O. S., Takuji I., Christina C., Peter R. C., Bridgett M. and Tanja H., "Fructokinase, Fructans, Intestinal Permeability, and Metabolic Syndrome: An Equine Connection", NIH Public Access., 33 (2), 120-126, 2013.

[8] Blatch G. L., and Woods D. R., "Molecular characterization of a fructanase produced by Bacteroides fragilis BF-1", J. Bacteriol., 175, 3058-66, 1993.

[9] Singh P. and Gill P. K., "Production of inulinases: Recent advances", Food Technol Biotechnol., 44,151-62, 2006. 
[10] Lopez-Molina D., Nawarro-Martinez M. D., Melgarejo F. R., Hiner A., Chazarra S., and Rodriguez-Lopez J. N., "Molecular properties and prebiotic effect of inulin obtained from artichoke (Cynara scolymus L)", Phytochemistry,66, 1476-1484, 2005.

[11] Maiorano A. E., Piccoli R. M., da Silva E. S., and de Andrade Rodrigues M. F., "Microbial production of fructosyltransferases for synthesis of prebiotics", Biotechnology Letters, 30, 1867-1877, 2008.

[12] Abdel-Fattah A. M., Gamal-Eldeen A. M., Helmy W. A. and Esawy M. A., "Antitumor and antioxidant activities of levan and its derivative from the isolate Bacillus subtilis NRC1aza", Carbohydrate Polymers, 89, 314-322, 2012.

[13] Rossi M., Corradini C., Amaretti A., Nicolini M., Pompei A., Zanoni S. and Matteuzzi D., "Fermentation of fructooligosaccharides and inulin by bifidobacteria: a comparative study of pure and fecal cultures", Appl. Environ. Microbiol., 71, 6150-6158, 2005.

[14] Brigitta K., Ludger H. and Michael B., "Fructans in the diet cause alterations of intestinal mucosal architecture, released mucins and mucosa-associated bifidobacteria in gnotobiotic rats", British Journal of Nutrition, 89, 597-606, 2003.

[15] Laura F., Mauro S. "Characterization of Pseudomonas spp. isolated from foods". Ann Microbiol, 57, 39-47, 2007.

[16] Pereira J. N., and Morgan M. E., "Nutrition and physiology of Pseudomonas". Journal of Bacteriol., 74, 710-713, 1957.

[17] Han Y. W. and Clarke M. A., "Production and characterization of microbial levan", J. Agric. Food Chem., 38, 393-396, 1990.

[18] Nagnath R., Mahesh V., Bule V. and Uday S., "Microbial Levan from Pseudomonas fluorescens: Characterization and Medium Optimization for Enhanced Production", Food Science and Biotechnology, 4, 1045-1053, 2012.

[19] Naja G. M., Mustin C. and Volesky B., "A high resolution; a new approach to studying binding site of microbial biosorbent", Water Research, 39, 579-588, 2005.
[20] Sener A. and Temez A., "In vitro study of some prebiotic properties of levan - type exopolysacchariede", FEMS, 2007.

[21] Laura F. and Mauro S., "Characterization of Pseudomonas spp. isolated from foods", Ann. Microbiol., 57, 39-47, 2007.

[22] Pereira J. N., and Morgan M. E., "Nutrition and physiology of Pseudomonas", J. Bacteriol. 74, 710-713, 1957.

[23] Garacia-Garibay M. and Marshall V. M., "Polymer production by Lactobacillus delberuckii spp. Bulgaricus", J. Appl. Bacteriol., 70, 325-328, 1991.

[24] Han Y. W. and Watson M. A., "Production of microbial levan from sucrose, sugarcane and beet molasses", Journal of Industrial Microbiology, 9, 257260, 1992.

[25] Han Y. W. and Clarke M. A., "Production of fructan (levan) polyfructose polymers using Bacillus polymyxa", United States Patent, 5547863, 1996.

[26] Back D. M. and Polavarapu P. L., "Fourier - transform Infrared spectroscopy of sugars. Structural changes in aqueous solutions", Carbohydrate Res., 121, 1983.

[27] Grube M., Bekers M., Upite D and Kaminska E., "IR-Spectroscopic studies of Zymomonas mobilis and levan precipitate", Vibrational Spectroscopy, 28, 277-285, 2002.

[28] Goh Y. J., Lee J. H. and Hutkins R. W., "Functional analysis of the fructooligosaccharide utilization operon in Lactobacillus paracasei 1195", Food Science and Technology, 18, 5716-5724, 2007.

[29] Lazar H. G., "Simposium: Probiotics and Prebiotics", Biotecnologia Aplicada., 20 (3), 189, 2003. 